windows, and the fresh external air is admitted through glazed channels regulated by valves. The fresh external air impinges upon the coils, and then streams into the ward. The separation ward ( 24 by 15 by $x 3$ feet) contains two beds, and has its own w.c. turret. The importance of this ward is great. Supposing, for instance, in the case of scarlet fever, symptoms arise which suggest the possible complication with measles, the patient would be at once transferred to the separation ward, and then, if the supposition becomes a certainty, from the separation ward to the isolation ward.

Isolation Wards.-Concurrent infectious diseases - errors in diagnosis-are events which necessitate in every infectious hospital isolation wards. At the Brook there are six isolation pavilions, two containing four single-bed wards each, and four having each one ward for four beds. Among 500 patients these wards will probably be more or less continuously occupied. It is, indeed, a question as to whether the accommodation for this purpose is not somewhat restricted.

Floors, Furniture, etc.-The details of construction also require commendatory notice-the teak floors, the walls plastered with Keene's cement, the great care to avoid ledges and recesses for the lodgment of dust; the windows, extending from $2 \mathrm{ft}$. 6 in. from the floor to close under the ceiling, giving the maximum of light; the solid birch furniture-all serviceable, substantial, and durable; and the electric lighting. Infection of the neighbourhood of the hospital would not be likely to occur on whatever plan the hospital was built, for experience is against the supposition. Nevertheless, the precaution of having two entrancesone for infetted persons and things, the other for non-infected persons and goods-is praiseworthy.

Laundry.-Two complete laundries have been provided-one for the patients and one for the staff. These laundries are provided with all the latest mechanical appliances for washing, drying, ironing, and so forth.

Drainage and Water Supply.-The drainage has been costly, for it was necessary to provide an outfall in the direction of Eltham. The water supply is that of the Kent Water Company, which will in part be softened by an apparatus provided by the Patent Heater Condensing Company. This apparatus will soften 60,000 gallons per day.

Disinfection. -The disinfecting apparatus is the "Equifex," and is by high-pressure steam. There is also a destructor. In this destructor all refuse from the wards and elsewhere will be destroyed.

Cost of the Hospital.-This is a serious matter, and open to most criticism. The hospital, including all fittings, apparatus, and machinery, has cost $£ 240,000$, the land about $£ 55^{\circ}$ per acre, which

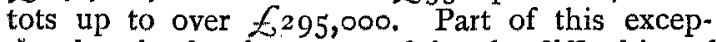
tional outlay has been caused by the difficulties of the site. The site was so undulating that large sums of money were sunk in levelling, etc., before a single stone was laid; but the main explanation is no doubt the general plan of construction and the large amount of space per bed. Considering that most of the scarlet fever patients will be children, it is a question whether without injury a less amount of cubic space might not have been given without any detriment to the chances of recovery. This lessened amount of cubic space might have been effected by a less height to the wards, the floor space remaining the same. On the other hand, if the Asylums Board will make free use of the remaining eight acres in times of epidemic-by the erection of temporary buildings - the cost of $£_{500}$ per bed will be in proportion reduced, and then no reasonable fault can be found with this, at first sight, extravagant sum of money.

Ambulance Station.-It should lastly be mentioned that a complete ambulance station has been erected close to the Brook Hospital, providing stabling for 16 horses, coach-houses for 20 ambulances, superintendent's residence and offices, home for 8 nurses, dining room, and cubicles for 25 drivers and other male servants, dining room and cubicles for 5 laundry maids and other female servants, together with kitchen, laundry, workshops, stores, etc. This has cost $\mathcal{E} \times 5,000$.

The Brook Hospital as a whole, with its ambulance station, may, therefore, be considered unrivalled in its completeness; it is palatial in the character of its accommodation ; its doors, so long as beds are vacant, will be open to every denizen, rich or poor, of the Metropolitan area to which it will be allotted. The hospital tends to complete the most marvellous example of efficient infectious disease isolation in the whole world.

\section{THE RELATIONSHIP OF WATER MAINS TO SEWERS**}

IY

M. J. OtIVER, M.B., D.P.H., M.O.H. of the County of Roxburgh.

AT Newtown the new water pipes were being laid beside and at a lower level than a sewer which was cracked and defective in many places. There was sewage actually lying in the bottom of the track in which the pipes were being laid on the occasion on which I made an inspection. This was reported to the District Committee, and the line of the water track was taken to the other side of the road, and the Committee decided to lay a new sewer below the level of the water pipes for the distance in which the pipes are in contiguity.

\footnotetext{
* From Dr. Oliver's Annual Report for 1895 .
} 
A committee of the County Council has reported in favour of this method of removing the danger of pollution of the water in the main, and the work will doubtless be proceeded with on the consent of the County Council being obtained for the necessary borrowation.

No information was received of similar works being undertaken at Denholm until, on a chance visit to the village, $I$ found them in progress. At the time of my visit the work was nearly completed and the new pipes covered in, a portion near the end being all that was visible. From this I was able to see that the same mistake had been made as at Newtown, and that the water pipes were below the level of the drains. Two or three of the drains which had been cut to allow of the main being laid I was able to see, and I heard from workmen of others which I could not see at the time. It being obvious that it was too late to stop the work, and have any immediate alteration made in the line of piping, I allowed the matter to rest until I had an opportunity of reporting to the Hawick District Committee. That body took no action beyond expressing regret that I had not reported sooner. At the succeeding meeting an account of my statement was sent to the Local Committee for consideration and observation, and, so far as I am aware, the following extract of the minutes of the meeting on December and shows the last action that has been taken by the Committee in relation to the matter:-

"Mr. Haddon, on behalf of the Local Committee of the Denholm Special Water Supply District, reported that the extract referred to in the minute of last meeting of the District Committee had been submitted to a meeting of the Local Committee held at Denholm on the 30 th ult.; and that while admitting that it would have been safer to have had the sewerage pipes deepened to a lower level than the water pipes, they (the Local Cornmittee) did not think there was at present any risk of leakage from the sewerage pipes, they having been perfectly sound and free from such when the water pipes were re-laid. They had, however, resolved that all sewerage drains to be laid or re-laid in future should, if at all possible, be laid at a lower level than the water pipes."

I regret that the Committee has taken no action since receiving the above report, and for the reason that, in my opinion, there is a danger of sewage gaining access to the water mains. It is well known that when leaks occur in piping, even those under an almost constant pressure of water, gas or liquid lying near the pipes may be drawn in by the power of suction exerted by the running water. This has been known to cause the pollution of town water by coal gas - an occurrence which Dr. Wynter Blyth, Medical Officer of Health to St. Marylebone, bears, witness has twice happened in his experience. He states that "defective mains or service pipes, although running full bore, may draw in polluting matters. It has been proved, experimentally, that a fluid flowing through a tube with defective joints, although the tube may be bore full, and at some pressure, yet a vacuum may occur at the joints, and any gas or liquid in contact with the joints sucked in."

Drs. Buchanan and Blaxall investigated two outbreaks of enteric fever, and found that sewage was sucked into mains from water-closets with which they were connected; while Dr. Spear gives an instance of an extensive epidemic being caused through water mains being laid, as those at Denholm and Newtown are, under and in close proximity to old drains. Dr. Carpenter, again, in the London Medical Record, 1872, says that sewage entering pipes may not produce serious results at once, and gives an instance in which no harm followed the contamination of water by sewage until the period of two years.

Defects in the sewage pipes may not be near the track of the water mains, but may yet cause harm, because sewage escaping from a sewer, except in an open soil, will follow the line of the sewer, and on reaching the line of the water pipes at a lower level will sink and follow it, possibly for a considerable distance. No one can guarantee that water mains and sewer pipes are free from defects, and safety can only be found by placing the pipes in such positions that if leaks do occur no harm will follow.

So long as the water mains and sewers are perfectly tight no harm can ensue on their being placed at improper levels; but it is impossible to trust to long lengths of either sewer or water piping remaining sound. The present method of rolling in metal on the roads is a severe trial to the strength of any piping not at a considerable depth. Other heavy traffic and the settling of the soil commonly cause fractures in pipes, and differences in the rate of expansion or contraction on changes in temperature may have the same result.

It appears to be extremely imprudent of Committees to hastily incur large liabilities without following the procedure which is obligatory by law, or satisfying themselves that the works undertaken are in accordance with the principles of sanitary science. The services of the County officials may be obtained free of cost, and no engineering scheme in relation to sanitation should be undertaken without the plans being submitted to their inspection and a report obtained showing what objections, if any, they may have to it. I have therefore to make the recommendation to the County Council that it be intimated to the different Committees concerned that no expenditure of capital on works will be authorised unless the plans have, previously to the work being commenced, been submitted to the County Council, and also that such plans be not passed unless they have been submitted for report either to the County officers or such other technical advice obtained as the Council may direct. 